\title{
Modificaciones de la microestructura y la capa pasiva de la aleación 2024-T3 Al-Cu durante una limpieza química empleada en la industria aeroespacial
}

\author{
Juan J. Alba-Galvín ${ }^{\mathrm{a}}$, Manuel Bethencourt ${ }^{\mathrm{b}, \varpi}$, Francisco J. Botana ${ }^{\mathrm{a}}$, Leandro González-Rovira ${ }^{\mathrm{a}}$, \\ José M. Sánchez-Amaya ${ }^{\mathrm{a}}$ \\ àDepartamento de Ciencia de Materiales e Ingeniería Metalúrgica y Química Inorgánica. Escuela Superior de Ingeniería, \\ Universidad de Cádiz, Avda. de la Universidad de Cádiz s/n, 11519, Puerto Real, España \\ ${ }^{b}$ Departamento de Ciencia de Materiales e Ingeniería Metalúrgica y Química Inorgánica. Facultad de Ciencias de Mar y \\ Ambientales-Instituto de Investigaciones Marinas (INMAR), Universidad de Cádiz, Avda. de la Universidad de Cádiz s/n, 11510, \\ Puerto Real, España \\ ( ${ }^{\boxplus}$ Autor para la correspondencia: manuel.bethencourt@uca.es)
}

Enviado: 26 Octubre 2018; Aceptado: 5 Marzo 2019; Publicado on-Line: 25 Junio 2019

\begin{abstract}
RESUMEN: Se han investigado los efectos de un pretratamiento superficial empleado en el sector aeroespacial sobre la aleación 2024-T3 Al-Cu antes de la generación de recubrimientos por conversión química. Estos pretratamientos influyen en las fases metálicas, que desempeñan un papel clave en el desarrollo de nuevos recubrimientos de conversión sin cromo y en la susceptibilidad a la corrosión localizada en medios que contienen cloruros. El pretratamiento estudiado consta de dos etapas alcalinas y una ácida. La microscopía electrónica de barrido reveló que después del proceso completo, las fases $\mathrm{Al}(\mathrm{Cu}, \mathrm{Mg})$ se eliminaban parcial o totalmente mediante desaleación y su posterior enriquecimiento de cobre, mientras que solo se atacó la matriz de aluminio que rodeaba las fases $\mathrm{Al}(\mathrm{Cu}, \mathrm{Fe}, \mathrm{Mn}, \mathrm{Si})$. El análisis electroquímico reveló el viraje a catódico de las fases $\mathrm{Al}(\mathrm{Cu}, \mathrm{Mg})$ que aún permanecen en la superficie mientras que la fases $\mathrm{Al}(\mathrm{Cu}, \mathrm{Fe}, \mathrm{Mn}, \mathrm{Si})$ presentaron un mayor potencial de corrosión que la matriz de aluminio. Por el contrario, ninguna de estas fases se vio afectada cuando se emplearon únicamente las dos etapas alcalinas. Identificados los procesos que tienen lugar cuando la aleación es sometida a un pretratamiento superficial, es posible diseñar sistemas de protección alternativos a los cromatos.
\end{abstract}

PALABRAS CLAVE: Aluminio; Corrosión; Fases de aleación; Pretratamientos superficiales

Citar como/Citation: Alba-Galvín, J.J.; Bethencourt, M.; Botana, F.J.; González-Rovira, L.; Sánchez-Amaya, J.M. (2019). "Modificaciones de la microestructura y la capa pasiva de la aleación 2024-T3 Al-Cu durante una limpieza química empleada en la industria aeroespacial". Rev. Metal. 55(2): e144. https://doi.org/10.3989/revmetalm.144

\begin{abstract}
Changes in the microstructure and passive layer of 2024-T3 Al-Cu alloy during a chemical cleaning employed in the aerospace industry. A standard surface pretreatment for 2024-T3 Al-Cu alloy prior to the generation of chemical conversion coatings in the aerospace sector have been investigated. These pretreatments influence the alloy phases, which play a key role in the development of new eco-friendly chromium-free conversion coatings, but also in the susceptibility to localized corrosion in chloride medium. The complete pretreatment consists of two alkaline step and another acid step. Scanning Electron Microscopy revealed that after the complete pretreatment, $\mathrm{Al}(\mathrm{Cu}, \mathrm{Mg})$ phases were partially or totally removed through dealloying with their subsequent copper enrichment, while only the aluminum matrix surrounding the $\mathrm{Al}(\mathrm{Cu}, \mathrm{Fe}, \mathrm{Mn}, \mathrm{Si})$ phases was slightly attacked. Electrochemical analysis revealed the turn to cathodic character of $\mathrm{Al}(\mathrm{Cu}, \mathrm{Mg})$ phases that still remain on the surface, while the $\mathrm{Al}(\mathrm{Cu}, \mathrm{Fe}, \mathrm{Mn}, \mathrm{Si})$ phases have a higher corrosion potential than the aluminum matrix. Conversely, none of these phases were affected when only alkaline steps were employed. Identified the corrosion processes that take place in the different phases when the alloy is treated with a surface pretreatment, it is possible to design alternative $\mathrm{Cr}$-free protective process
\end{abstract}

KEYWORDS: Alloy phases; Aluminum; Corrosion; Surface pretreatments

ORCID: Juan Jesús Alba-Galvín (https://orcid.org/0000-0002-4163-3280); Manuel Bethencourt (https://orcid. org/0000-0002-0488-7097); Francisco Javier Botana (https://orcid.org/0000-0002-1134-2669); Leandro GonzálezRovira (https://orcid.org/0000-0003-1865-5294); José María Sánchez-Amaya (https://orcid.org/0000-0002-4575-5103)

Copyright: (C) 2019 CSIC. Este es un artículo de acceso abierto distribuido bajo los términos de la licencia de uso y distribución Creative Commons Reconocimiento 4.0 Internacional (CC BY 4.0). 


\section{INTRODUCCIÓN}

Las aleaciones de $\mathrm{Al}-\mathrm{Cu}$ comúnmente empleadas por las industrias aeroespacial y automovilística en componentes estructurales ofrecen una excelente relación entre peso y propiedades mecánicas gracias a sus aleantes. Las principales fases intermetálicas en la aleación 2024 son $\mathrm{Al}(\mathrm{Cu}, \mathrm{Mg})$, conocida como Fase-S o $\mathrm{Al}_{2} \mathrm{CuMg}$, y $\mathrm{Al}(\mathrm{Cu}, \mathrm{Fe}, \mathrm{Mn}, \mathrm{Si})$, con diferentes estequiometrías en función del autor consultado. Sin embargo, sobre estos precipitados se produce la reducción de $\mathrm{O}_{2}$ que posibilita procesos de corrosión filiforme o por picaduras. Como consecuencia, las aleaciones de $\mathrm{Al}-\mathrm{Cu}$ son tratadas con una amplia variedad de tratamientos superficiales para evitar los efectos de la corrosión. En muchos de ellos se han empleado tradicionalmente cromatos en forma de inhibidores, en pinturas, capas de conversión química o anodizados (Eichinger et al., 1997; Osborne, 2001; Kendig y Bucheheit, 2003). Lamentablemente, el cromo, en especial el $\mathrm{Cr}(\mathrm{VI})$, es tóxico y cancerígeno, por lo que las leyes y regulaciones como REACH (Registration, Evaluation, Authorisation and Restriction of Chemicals) están forzando a industria e investigadores a sustituirlo por alternativas menos tóxicas y más ecológicas (Eichinger et al., 1997; Twite y Bierwagen, 1998; Montemor, 2014). Hasta el momento se han concedido sucesivas moratorias y se ha restringido el uso de cromo con controles cada vez más estrictos.

Algunos tratamientos superficiales, como el anodizado crómico (CAA), cuentan con alternativas al empleo de cromo en diferentes estados de progreso, pero otros, como las capas de conversión química, necesitan aun de nuevas tecnologías. Entre el amplio abanico de alternativas al empleo de capas de conversión basadas en cromatos que han sido investigadas destacan los molibdatos, permanganatos, oxifluoruros metálicos (principalmente Ti/Zr), fosfatos, silanos, Sol-Gel y elementos de tierras raras (especialmente Ce) (Twite y Bierwagen, 1998; Kulinich and Akhtar, 2012; Harvey, 2013). En todas estas tecnologías la microestructura y química superficial del metal son de una importancia capital para el desarrollo de los diferentes mecanismos de formación del recubrimiento y su posterior comportamiento. Sin embargo, varios artículos de revisión recientes reconocen que los pretratamientos previos a la formación de la capa de conversión no han recibido la atención requerida. Kulinich y Akhtar (2012) afirman que son necesarios aun muchos estudios para comprender mejor las relaciones entre microestructura, pretratamientos y composición química de las disoluciones en las que se forma el recubrimiento. Harvey (2013) concluye en su revisión del caso particular de las capas de conversión basadas en Ce que un aspecto necesario para su desarrollo final es comprender mejor el efecto de los pretratamientos superficiales previos y adaptarlos a escala industrial.
En este contexto, el objetivo de este trabajo es investigar el efecto de una cadena de pretratamientos de aleaciones de aluminio comúnmente empleados en el sector aeroespacial. En concreto, son tres disoluciones de los productos comerciales:

Henkel/Turco 6849: desengrasante alcalino formulado para eliminar aceites, grasas y otros residuos orgánicos. Compuesto por $\mathrm{C}_{8} \mathrm{H}_{11} \mathrm{NaO}_{3} \mathrm{~S}(5-10 \%)$, $\left(\mathrm{OC}_{2} \mathrm{H}_{4}\right)_{\mathrm{n}} \mathrm{OH}(5-10 \%)$, tensioactivos $(5-10 \%)$ y $\mathrm{C}_{2} \mathrm{H}_{7} \mathrm{NO}(1-5 \%)$.

Henkel/Turco 4215 NC-LT: limpiador alcalino de metales ferrosos y no ferrosos. Compuesto por: $\mathrm{Na}_{2} \mathrm{~B}_{4} \mathrm{O}_{7} \cdot 10 \mathrm{H}_{2} \mathrm{O} \quad(30-60 \%) \quad \mathrm{Na}_{5} \mathrm{P}_{3} \mathrm{O}_{10} \quad(10-30 \%)$, $\mathrm{NaNO}_{3}(5-10 \%), \mathrm{C}_{8} \mathrm{H}_{18} \mathrm{O}_{3}(1-5 \%)$ y Na $2 \mathrm{SiF}_{6}(1-5 \%)$.

Henkel/Turco Smut Go NC: decapante ácido elaborado para eliminar la capa pasiva y restos de otros óxidos. Compuesto por: $\mathrm{Fe}_{2}\left(\mathrm{SO}_{4}\right)_{3}(30-60 \%)$, $\mathrm{HNO}_{3}(5-10 \%), \mathrm{NaHF}_{2}(1-5 \%)$ y $\mathrm{H}_{2} \mathrm{SO}_{4}(0.1-1 \%)$.

Aunque hay un importante número de trabajos que emplean alguno de estos pretratamientos antes de aplicar tratamientos anticorrosivos, solo algunos analizan los cambios producidos en la aleación (Pinc et al., 2009; Guo y Frankel, 2012; Li et al., 2014; Viroulaud et al., 2017). De hecho, los autores no han detectado ninguna referencia que describa los efectos de estos tres pretratamientos empleados de manera consecutiva sobre la aleación 2024-T3. La elección de una cadena de tratamientos comercial ya implantada se basa en el conocimiento de que la exigente normativa de calidad del sector aeroespacial aceptaría con mayor celeridad aquellos tratamientos que continúen usando los pretratamientos ya normalizados o con el menor número de modificaciones sobre los ya existentes.

\section{MATERIALES Y MÉTODOS}

\subsection{Aleación}

Se ha elegido la aleación AA2024-T3, de uso común en la industria aeroespacial, cuyos aleantes principales son $\mathrm{Cu}(4,30 \%$ peso), $\mathrm{Mg},(1,30 \%$ peso), Mn $(0,58 \%$ peso $)$ y $\mathrm{Fe}(0,19 \%$ peso $)$. Las muestras empleadas fueron de $80 \times 25 \times 0,8 \mathrm{~mm}$.

\subsection{Tratamientos}

Los baños se han preparado siguiendo la norma I+D+P-072 (2009). El baño de Turco 6849 tenía un pH de 10,7 y se sumergieron las muestras durante $7 \mathrm{~min}$ a $55^{\circ} \mathrm{C}$. La disolución de Turco $4215 \mathrm{NC}$-LT tiene un $\mathrm{pH}$ de 8,9 y se aplicó durante $10 \mathrm{~min}$ a $50^{\circ} \mathrm{C}$. Finalmente, el decapante Smut Go NC presenta un $\mathrm{pH}$ de 1,2 y se empleó a temperatura ambiente durante $5 \mathrm{~min}$.

La serie concatenada de tres tratamientos se ha codificado como tts, correspondiente a las iniciales del nombre comercial del producto empleado en cada etapa. Asimismo, se ha estudiado el proceso parcial tt, que resulta de eliminar el baño de decapado ácido. 
Tras la aplicación de cada uno de estos tratamientos, las muestras se enjuagaban en duchas de agua desionizada ( $\mathrm{pH} 5,6$, resistividad $15 \mathrm{M} \Omega$ ) durante 1 min seguido de 3 min de inmersión.

\subsection{Caracterización superficial}

Utilizando un microscopio electrónico de barrido Hitachi SU 1510 se caracterizaron muestras embutidas y pulidas hasta $3 \mu \mathrm{m}$ para obtener imágenes de Microscopía Electrónica de Barrido (SEM) e información composicional empleando Espectrometría de Dispersión de Energía de Rayos X (EDX).

Sellevaron a cabo análisis mediante Espectrometría Fotoelectrónica de Rayos-X (XPS) con un equipo Kratos AXIS Ultra DLD empleando radiación Al K $\alpha$ (1486.6eV) y una potencia de Rayos-X de $150 \mathrm{~W}$. Los efectos superficiales de carga fueron compensados usando el sistema de neutralización coaxial Kratos. El espectrómetro operó en modo constante de energía de análisis, con un paso de $20 \mathrm{eV}$. Los datos fueron tratados con el software CasaXPS 2.3.18PR1.0.

\subsection{Ensayos electroquímicos}

Los registros de polarización lineal (PL) se realizaron en una celda de tres electrodos, en disolución de $\mathrm{NaCl} 0,59 \mathrm{M}$ y empleando un potenciostato
Autolab PGSTAT302N controlado por el software NOVA 2.1.2. Se utilizó un electrodo de referencia de $\mathrm{Ag} / \mathrm{AgCl}$ de Metrohm (0,207 V/SHE, $\left.25^{\circ} \mathrm{C}\right)$. Como contraelectrodo se empleó grafito. La superficie de trabajo fue de $1 \mathrm{~cm}^{2}$. Previamente a PL, las muestras se mantuvieron durante 1 hora a circuito abierto para establecer el potential de corrosión $\left(\mathrm{E}_{\text {corr }}\right)$. Las polarizaciones se llevaron a cabo desde $-0,025 \mathrm{~V}$ hasta $1 \mathrm{~V}$ frente a $\mathrm{E}_{\text {corr }}$, a una velocidad de $0,17 \mathrm{mV} \cdot \mathrm{s}^{-1}$. La actividad electroquímica de las muestras se analizó en función del valor de resistencia a la polarización $\left(\mathrm{R}_{\mathrm{p}}\right)$ calculado a través de la ecuación de Stern-Geary (González Fernández, 1989).

\section{RESULTADOS}

\subsection{Influencia de los pretratamientos superficiales en la aleación AA2024-T3}

\subsubsection{Caracterización superficial mediante $S E M-E D X$}

En la Fig. 1 se muestran imágenes SEM de una zona sin tratar y una vez sometida a la combinación de tratamientos tt y tts. Comparando las Fig. 1(a b) no se aprecian cambios ni en la matriz ni en los intermetálicos tras el tratamiento tt. En la Fig. 1(c) se observa un revelado de la matriz con diferentes
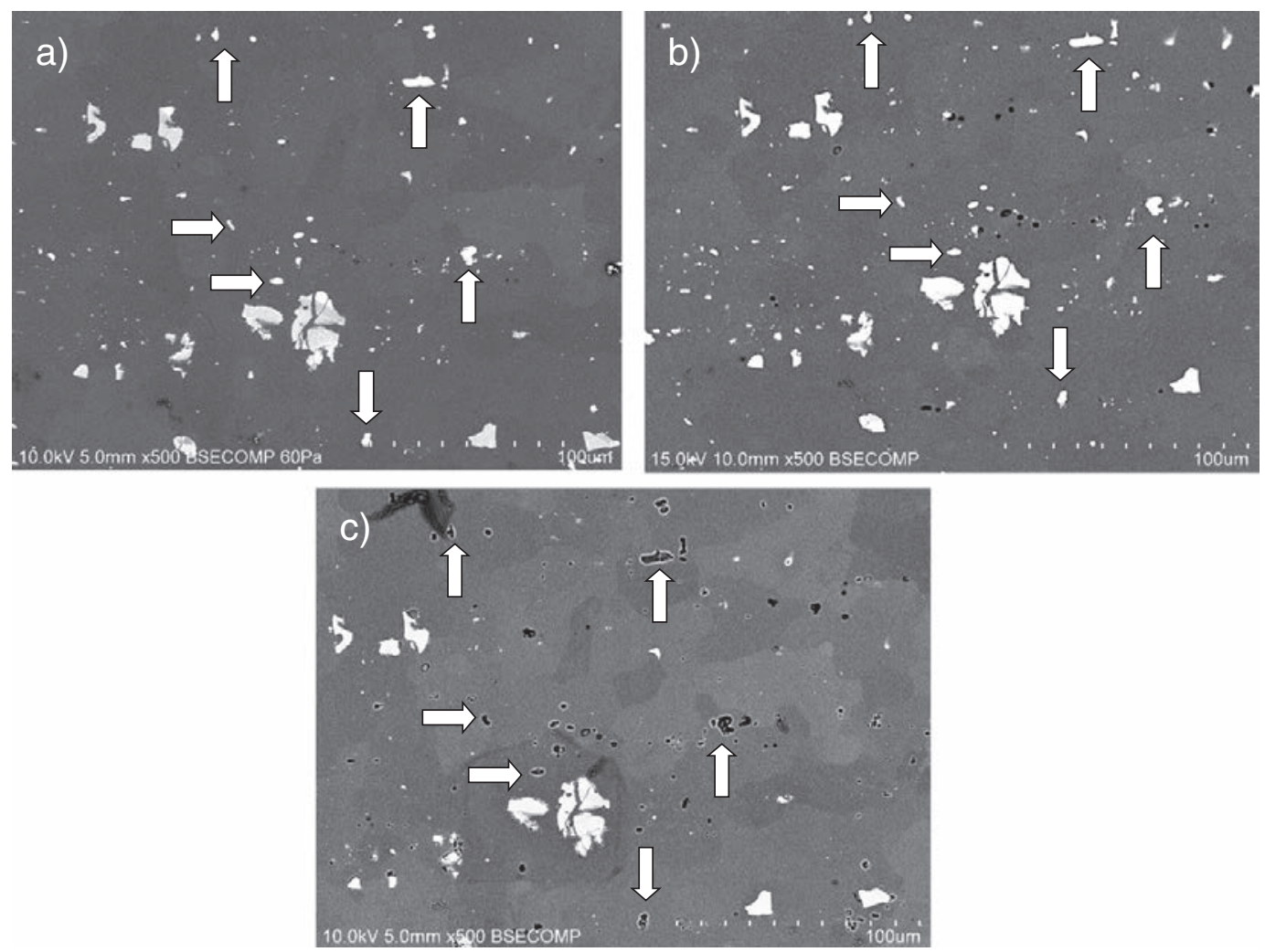

FIGURA 1. Imágenes SEM de una muestra: a) sin tratar, b) tras los pretratamientos $\mathrm{tt}, \mathbf{y}$ c) tras los pretratamientos tts. Las flechas blancas señalan la evolución de los precipitados durante las distintas fases. 
contrastes posterior al tratamiento tts. Teniendo en cuenta que las imágenes están tomadas en modo de electrones retrodispersados, es decir, que su contraste se debe fundamentalmente a diferencias en número atómico, estas zonas han debido sufrir algún tipo de modificación química. Por otro lado, se produce una pérdida de intermetálicos.

En la Fig. 2 se observan tres imágenes SEM de intermetálicos $\mathrm{Al}(\mathrm{Cu}, \mathrm{Fe}, \mathrm{Mn}, \mathrm{Si})$ de una muestra sin tratar y tras los tratamientos tt y tts, así como los espectros EDX puntuales registrados en las zona marcadas en las imágenes. Se pone de manifiesto que no se ha producido un desprendimiento de los intermetálicos $\mathrm{Al}(\mathrm{Cu}, \mathrm{Fe}, \mathrm{Mn}, \mathrm{Si})$, si bien después del tratamiento tts, la matriz en las inmediaciones del intermetálico $\mathrm{Al}(\mathrm{Cu}, \mathrm{Fe}, \mathrm{Mn}, \mathrm{Si})$ ha sido atacada.

En la Tabla 1 se presentan los resultados de la cuantificación atómica de diferentes tipos de intermetálicos. Se tomó como una composición atómica del 100\% la suma de los porcentajes de los diferentes elementos que componen el intermetálico. En el caso de los intermetálicos $\mathrm{Al}(\mathrm{Cu}, \mathrm{Fe}, \mathrm{Mn}, \mathrm{Si})$ se cuantificaron tres EDX puntuales. Los resultados indican que esta fase no sufre modificaciones significativas desde el punto de vista estadístico. No obstante, el incipiente ataque en la matriz adyacente y la aparente tendencia a disminuir el contenido de Fe y Mn y de aumentar el de Al inclinan a pensar en modificaciones en su composición de en torno al $30 \%$ en el caso del Fe, el $20 \%$ para el Mn y del 10\% en $\mathrm{Al}$, atendiendo a los cambios experimentados por los valores promedios incluidos en la Tabla 1.

Por su parte, los intermetálicos $\mathrm{Al}(\mathrm{Cu}, \mathrm{Mg})$ sufrieron dos efectos diferentes tras el tratamiento tts. En la mayoría de los casos se observó un desprendimiento, y en menores ocasiones adquiría una forma esponjosa. En la Fig. 3 se ilustra un ejemplo de desprendimiento. Se incluyen imágenes SEM de intermetálicos del tipo $\mathrm{Al}(\mathrm{Cu}, \mathrm{Mg})$ en una zona sin tratar, tras los tratamientos tt y tts, Fig. 3 (a-b-c), respectivamente. Se muestran también en la Fig. 3(d) los espectros EDX puntuales adquiridos sobre la partícula marcada en las imágenes SEM. La pérdida del intermetálico se observa con el tratamiento tts, Fig. 3(c). La cuantificación realizada sobre los espectros EDX, Tabla 1, confirma que el análisis realizado después del tratamiento tts se ha producido sobre la matriz de aluminio, puesto que aproximadamente el 97\% de átomos son de Al.

Por otro lado, en la Fig. 4 se observan ejemplos de formación de estructuras esponjosas. Nuevamente estas figuras incluyen imágenes SEM antes y después de los tratamientos tt y tts, junto a los espectros EDX de la marcada con línea continua.

En la Fig. 4(d) se comprueba que el hecho más destacable es la pérdida del pico correspondiente al $\mathrm{Mg}$ en la muestra tts. Efectivamente, en la Tabla 1 se observa asimismo que el tratamiento tts provoca una disminución en la composición de $\mathrm{Mg}$ prácticamente a valores nulos, con el consiguiente incremento en el contenido de $\mathrm{Cu}$.

Si se comparan las composiciones iniciales de los intermetálicos $\mathrm{Al}(\mathrm{Cu}, \mathrm{Mg})$ desprendidos y los que permanecen con forma esponjosa, se observa que estos últimos contienen más aluminio, aproximadamente $70 \%$ frente a $60 \%$, y menos magnesio, aproximadamente $10 \%$ frente a $20 \%$. Mientras, el cobre se sitúa en torno al $20 \%$ en ambos casos.

\subsubsection{Caracterización superficial mediante XPS}

En la Fig. 5(a) se muestra el espectro XPS a alta resolución correspondiente al Al 2p de las muestras sin tratar, tt y tts, con picos a valores de 72,60 y $75,60 \mathrm{eV}$, asociados a la energía de ligadura Al-Al, indicativo del aluminio metálico y a la energía de ligadura $\mathrm{Al}-\mathrm{O}$, indicativo del $\mathrm{Al}_{2} \mathrm{O}_{3}$.

La relación de las intensidades de ambos picos, $\mathrm{I}_{\mathrm{Ox}} / \mathrm{I}_{\mathrm{Met}}$, se emplea para estimar el espesor de la capa pasiva de las muestras (Moffitt et al., 2001; Hughes et al., 2005; Viroulaud et al., 2017; Tiringer et al., 2017) a través de la Ec. (1), propuesta por Strohmeier (1990).

$$
\mathrm{d}=\lambda_{\text {Almet }}^{\text {Alox }} \cdot \operatorname{Ln}\left[1+1.341 \cdot \frac{\text { Iox }}{\text { Imet }}\right]
$$

Siendo d el espesor de la capa pasiva en nanometros y $\lambda_{\text {Almet }}^{\text {Alox }}$ una constante con un valor de $3,510^{-9}$ m. Los valores de espesores de la capa pasiva (d) calculados son de 6,$4 ; 6,4$ y 3,2 $\mathrm{nm}$ para las muestras sin tratar, tt y tts, respectivamente.

Se incluye igualmente en la Fig. 5(b) el espectro XPS a alta resolución correspondiente al $\mathrm{Cu} 2 \mathrm{p}_{3 / 2}$ de las muestras tt y tts con pico a $933 \mathrm{eV}$. En la muestra sin tratar no se observo esté pico de cobre.

\subsubsection{Caracterización electroquímica}

En la Fig. 6 y en la Tabla 2 pueden observarse las curvas PL en $\mathrm{NaCl}$ 0,59 $\mathrm{M}$ aireado y los valores de los parámetros electroquímicos extraídos de las mismas. Los valores del $\mathrm{E}_{\text {corr }}$ de las muestras sin tratar $\mathrm{y}$ tt son muy próximos, situándose en $-0,561 \mathrm{~V}$ y $-0,557 \mathrm{~V}$ vs Ag/AgCl (0,207 V/SHE). El potencial de nucleación de picaduras se encuentra en torno a $-0,540 \mathrm{~V}$ en ambas muestras, solo ligeramente superior a $\mathrm{E}_{\text {corr }}$.

En el caso de las muestras tts se aprecia un desplazamiento de la rama catódica hacia menores valores de densidades de corriente y de $\mathrm{E}_{\text {corr }}$ hacia valores más negativos.

\section{DISCUSIÓN}

Mediante SEM-EDX se detectaron los dos intermetálicos principales de la aleación 2024T3: $\mathrm{Al}(\mathrm{Cu}, \mathrm{Mg})$ y $\mathrm{Al}(\mathrm{Cu}, \mathrm{Fe}, \mathrm{Mn}, \mathrm{Si})$. La mayoría 

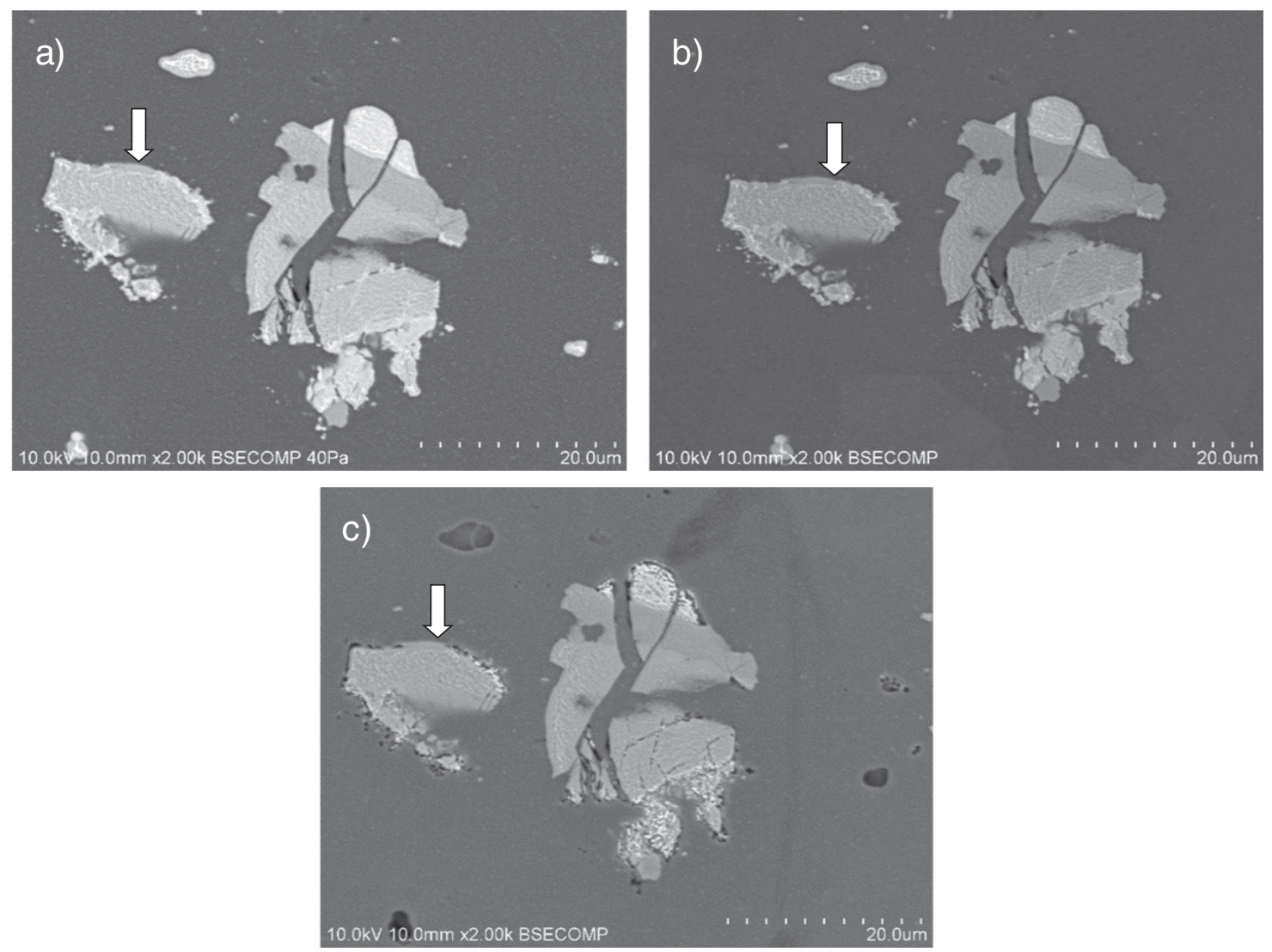

d)

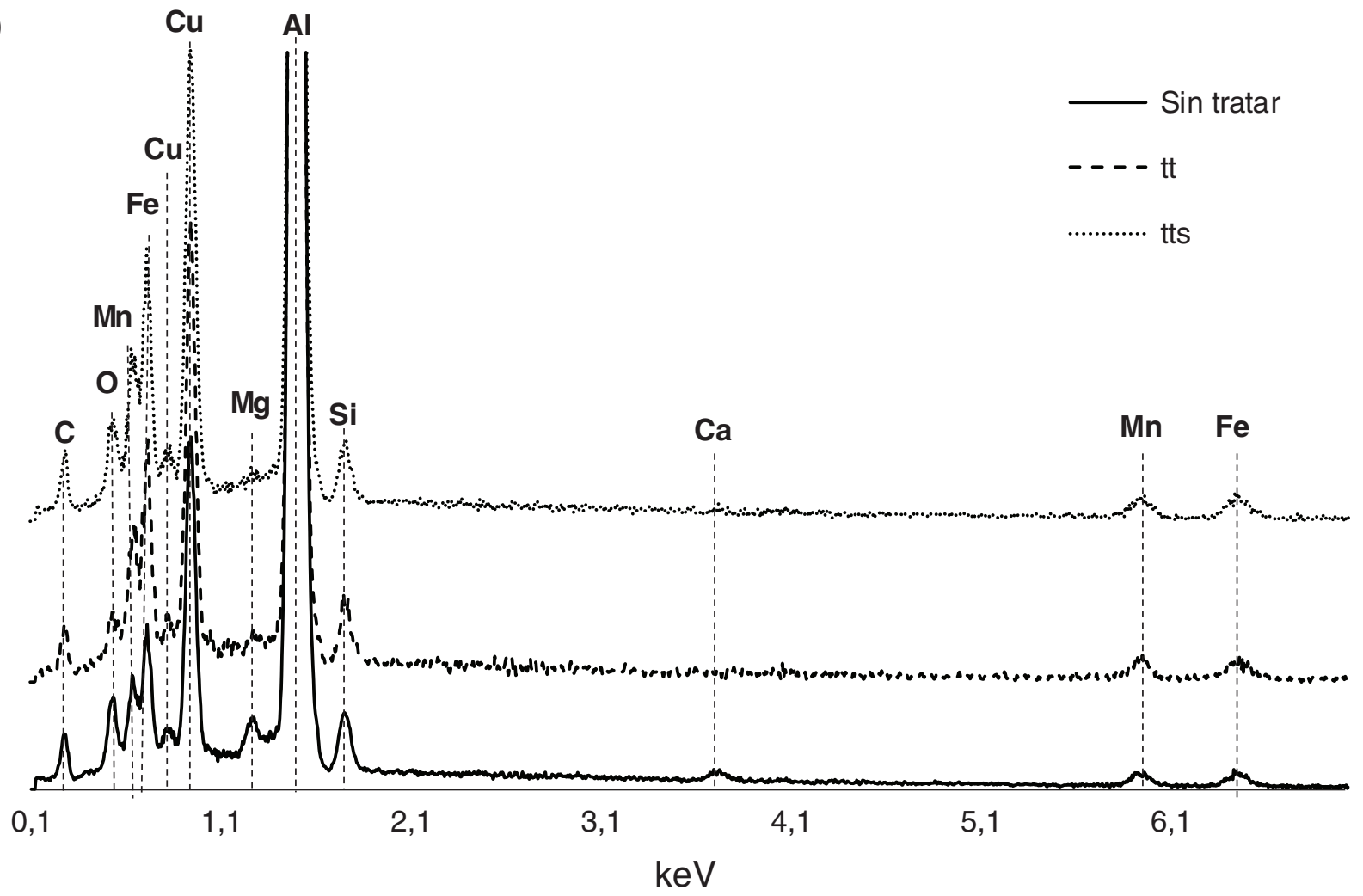

Figura 2. Imágenes $\mathrm{SEM}$ de intermetálico $\mathrm{Al}(\mathrm{Cu}, \mathrm{Fe}, \mathrm{Mn}, \mathrm{Si})$ de una muestra: a) sin tratar, $\mathrm{y}$ tras los tratamientos, b) tt y c) tts d) Superposición de los espectros EDX puntuales registrados sobre la partícula indicada con flechas en las figuras a), b) y c). 
TABla 1. Cuantificación de los elementos que componen diferentes intermetálicos en muestras sin tratar y con tratamientos tt y tts

\begin{tabular}{|c|c|c|c|c|c|c|c|c|c|}
\hline & \multicolumn{3}{|c|}{$\mathrm{Al}(\mathrm{Cu}, \mathrm{Fe}, \mathrm{Mn}, \mathrm{Si})$} & \multicolumn{3}{|c|}{ Fase-S desprendida } & \multicolumn{3}{|c|}{ Fase-S no desprendida } \\
\hline & Sin tratar & $\mathrm{tt}$ & tts & Sin tratar & tt & tts & Sin tratar & tt & tts \\
\hline Al & $67,3 \pm 5,4$ & $73,2 \pm 5,2$ & $74,5 \pm 3,3$ & $56,3 \pm 5,1$ & $60,3 \pm 5,1$ & $97,4 \pm 1,3$ & $70,0 \pm 0,1$ & $69,9 \pm 4,5$ & $70,7 \pm 4,8$ \\
\hline $\mathbf{C u}$ & $12,0 \pm 2,3$ & $10,7 \pm 5,6$ & $12,5 \pm 3,9$ & $27,0 \pm 4,9$ & $19,2 \pm 1,2$ & $1,2 \pm 0,2$ & $20,8 \pm 0,4$ & $19,8 \pm 2,9$ & $28,7 \pm 4,2$ \\
\hline $\mathrm{Fe}$ & $11,9 \pm 2,2$ & $8,9 \pm 0,5$ & $8,2 \pm 2,3$ & - & - & - & - & - & - \\
\hline Mn & $6,1 \pm 0,9$ & $5,6 \pm 0,4$ & $4,9 \pm 1,4$ & - & - & - & - & - & - \\
\hline $\mathbf{S i}$ & $2,8 \pm 0,6$ & $1,6 \pm 1,0$ & $1,9 \pm 0,6$ & - & - & - & - & - & - \\
\hline Mg & - & - & - & $16,8 \pm 6,6$ & $20,2 \pm 3,6$ & $1,1 \pm 0,8$ & $9,2 \pm 0,2$ & $10,3 \pm 1,6$ & $0,6 \pm 0,7$ \\
\hline
\end{tabular}

de autores (Hughes et al., 2005; Boag et al., 2009; DeRose et al., 2012; Glenn et al., 2013) coinciden en asignarle a $\mathrm{Al}(\mathrm{Cu}, \mathrm{Mg})$ una forma redondeada de 5-8 $\mu \mathrm{m}$ de diámetro aproximadamente y una estequiometría $\mathrm{Al}_{2} \mathrm{CuMg}$. No obstante, otros autores defienden que $\mathrm{Al}(\mathrm{Cu}, \mathrm{Mg})$ se encuentra generalmente conglomerada con otro tipo de intermetálico minoritario, $\mathrm{Al}_{2} \mathrm{Cu}$ o Fase- $\theta$, formando una mezcla denominada $\mathrm{s} / \theta$. Así $\mathrm{Al}(\mathrm{Cu}, \mathrm{Mg})$ puede presentar distintas estequiometrías con pequeñas variaciones en función del contenido en Fase- $\theta$. El segundo tipo de fase es $\mathrm{Al}(\mathrm{Cu}, \mathrm{Fe}, \mathrm{Mn}, \mathrm{Si})$. En este caso, la discusión sobre su estequiometria no está cerrada, aunque algunos autores han propuesto $(\mathrm{Al}, \mathrm{Cu})_{11}(\mathrm{Fe}, \mathrm{Mn})_{7} \mathrm{Si}$ (Gao et al., 1998), y se han descrito en un intervalo de tamaño que va de unos cuantos micrómetros hasta aproximadamente $15 \mu \mathrm{m}$ de diámetro.

En primer lugar, es necesario indicar que el desengrase alcalino con Turco 6849 no tiene efectos en la aleación metálica. En cambio, el Turco 4215 NC-LT podría atacar levemente la capa pasiva debido a que presenta un $\mathrm{pH}$ en torno 9 y a que contiene el compuesto fluorado $\mathrm{Na}_{2} \mathrm{SiF}_{2}$ y el trifosfatado $\mathrm{Na}_{5} \mathrm{P}_{3} \mathrm{O}_{10}$. Por un lado los aniones $\mathrm{F}^{-}$disolverían la capa pasiva (Cerezo et al., 2014; Qi et al., 2015) a través de la reacción química Ec. (2), dando lugar a un conjunto de fluoruros de aluminio.

$$
\mathrm{Al}_{2} \mathrm{O}_{3}(\mathrm{~s})+\mathrm{xF}^{-}(\mathrm{aq})+6 \mathrm{H}^{+}(\mathrm{aq}) \rightarrow \mathrm{AlF}_{\mathrm{x}}^{(3-\mathrm{x})}(\mathrm{aq})+3 \mathrm{H}_{2} \mathrm{O}(\mathrm{l})
$$

No obstante, la reacción química Ec. (2) no tendrá un rendimiento muy alto debido a que el tratamiento es en medio básico. La otra reacción es la que tiene lugar entre los cationes $\mathrm{Al}^{3+}$ y los aniones $\mathrm{PO}_{4}{ }^{-3}$ (Rayner-Canham, 2000; Qi et al., 2015; Qi et al., 2016), reacción química Ec. (3), permitiendo la eliminación de $\mathrm{Al}^{3+}$ del medio $\mathrm{y}$, por consiguiente, favoreciendo la disolución de la capa pasiva.

$$
\mathrm{Al}^{3+}(\mathrm{aq})+\mathrm{PO}_{4}^{3-}(\mathrm{aq}) \rightarrow \mathrm{AlPO}_{4}(\mathrm{~s})
$$

Sin embargo, la caracterización realizada mediante SEM-EDX revela que el tratamiento tt no produce modificaciones relevantes nien la matriznien los intermetálicos, Fig. 1. En el mismo sentido, los análisis de XPS indican la ausencia de ataque apreciable, pues el espesor de la capa pasiva se mantiene constante respecto de la muestra sin tratar. Estos resultados indican que las potenciales reacciones de ataque a la alúmina no se producen, o lo hacen de un modo muy leve. Pinc et al. (2009) describen un resultado similar en el que mediante análisis de Espectrometría de Electrones Auger detectan una leve reducción del espesor de alúmina de 30 a $25 \mathrm{~nm}$.

Por otro lado, el estudio SEM-EDX tras el tratamiento tts revela tanto ataques a los intermetálicos $\mathrm{Al}(\mathrm{Cu}, \mathrm{Mg})$ como a la alúmina pasiva durante el tratamiento con Smut Go NC. En el caso de los intermetálicos podemos considerar dos comportamientos diferentes, uno en el que adoptan una forma de esponja, (Fig. 4) y otro en donde desprenden de la matriz metálica (Fig. 3). Cuando permanecen sobre la matriz, los espectros EDX mostraron la disminución drástica de $\mathrm{Mg}$ y un aumento de $\mathrm{Cu}$, permaneciendo constante el Al, Fig. 4(d). Esta observación es similar a la descrita por otros autores como Guillaumin y Mankowski (1998), Yasakau et al. (2006) y Bethencourt et al. (2009), para diferentes medios agresivos, en los que se produce la desaleación selectiva de $\mathrm{Mg}$ en Fases-S de aluminio 2024 hasta adquirir una estequiometria $\mathrm{Al}_{2} \mathrm{Cu}$. Posteriormente, tiene lugar la oxidación de $\mathrm{Al}$ a $\mathrm{Al}^{3+}$, dando lugar a una nueva desaleación selectiva en $\mathrm{Al}$ y un enriquecimiento en $\mathrm{Cu}$ hasta que se produce el desprendimiento del intermetálico.

En nuestro caso, como ya se ha comentado en la sección 3.1.1, en la Tabla 1 se comprueba que los intermetálicos que persisten con forma esponjosa tienen inicialmente un mayor contenido en $\mathrm{Al}$ $\mathrm{y}$ menor contenido en $\mathrm{Mg}$ que los que posteriormente se desprenderán. Esta diferencia es coherente con el mecanismo de desaleación descrito, pues es razonable que las fases que hayan perdido menos volumen en forma de $\mathrm{Mg}^{2+}$ tengan más probabilidad de permanecer en su lugar. De acuerdo con esto, $\mathrm{Al}(\mathrm{Cu}, \mathrm{Mg})$ permanece como esponjosa tras 

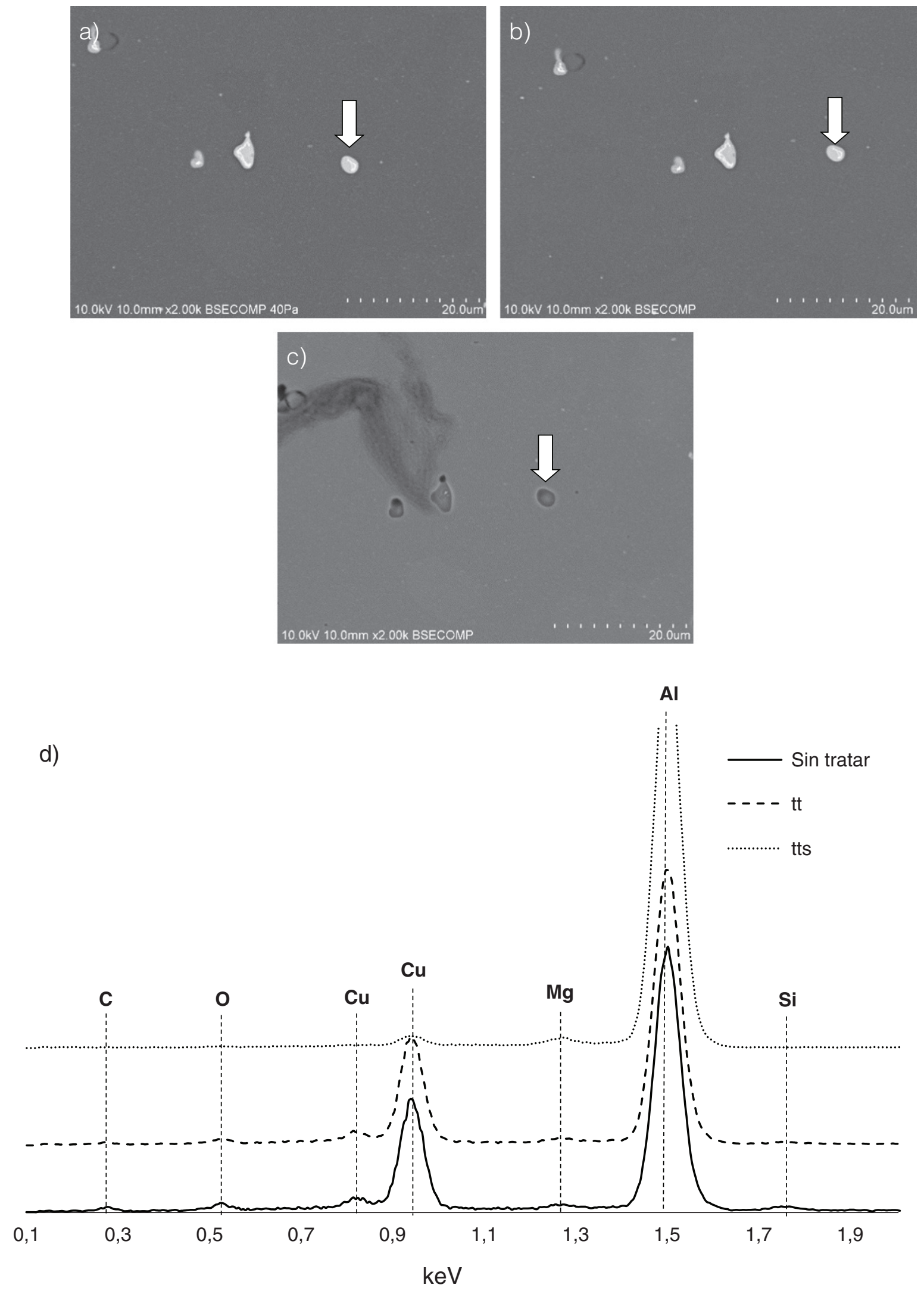

Figura 3. Imágenes SEM de Fase-S: a) sin tratar y tras los tratamientos, b) tt, c) tts, y d) Superposición de los espectros EDX puntuales registrados sobre la partícula indicada con flechas en las figuras a), b) y c). 

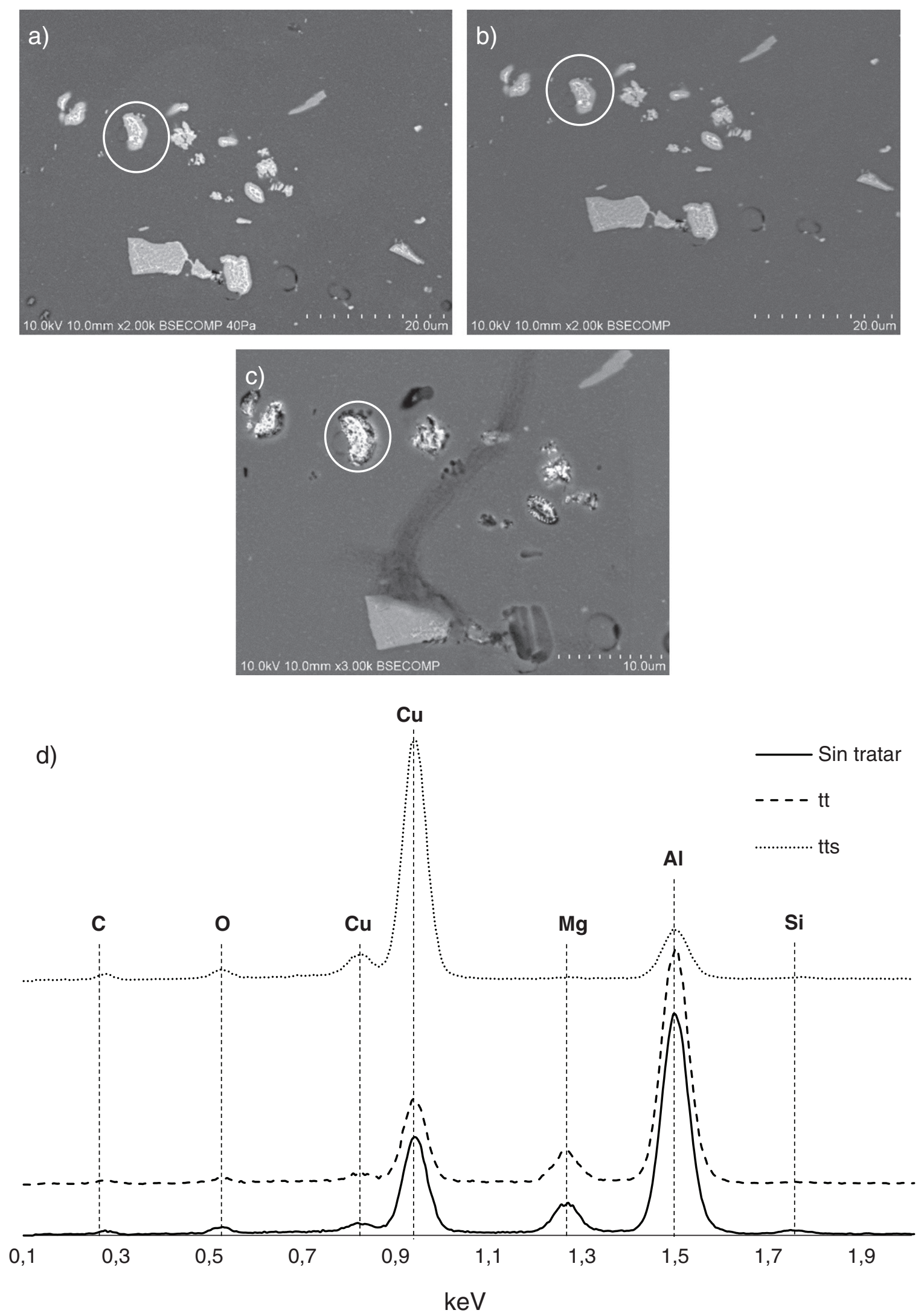

FIgura 4. Imágenes SEM de Fase-S: a) sin tratar y tras los tratamientos, b) tt, c) tts, y d) Superposición de los espectros EDX puntuales registrados sobre la partícula indicada con un círculo en las figuras a), b) y c). 

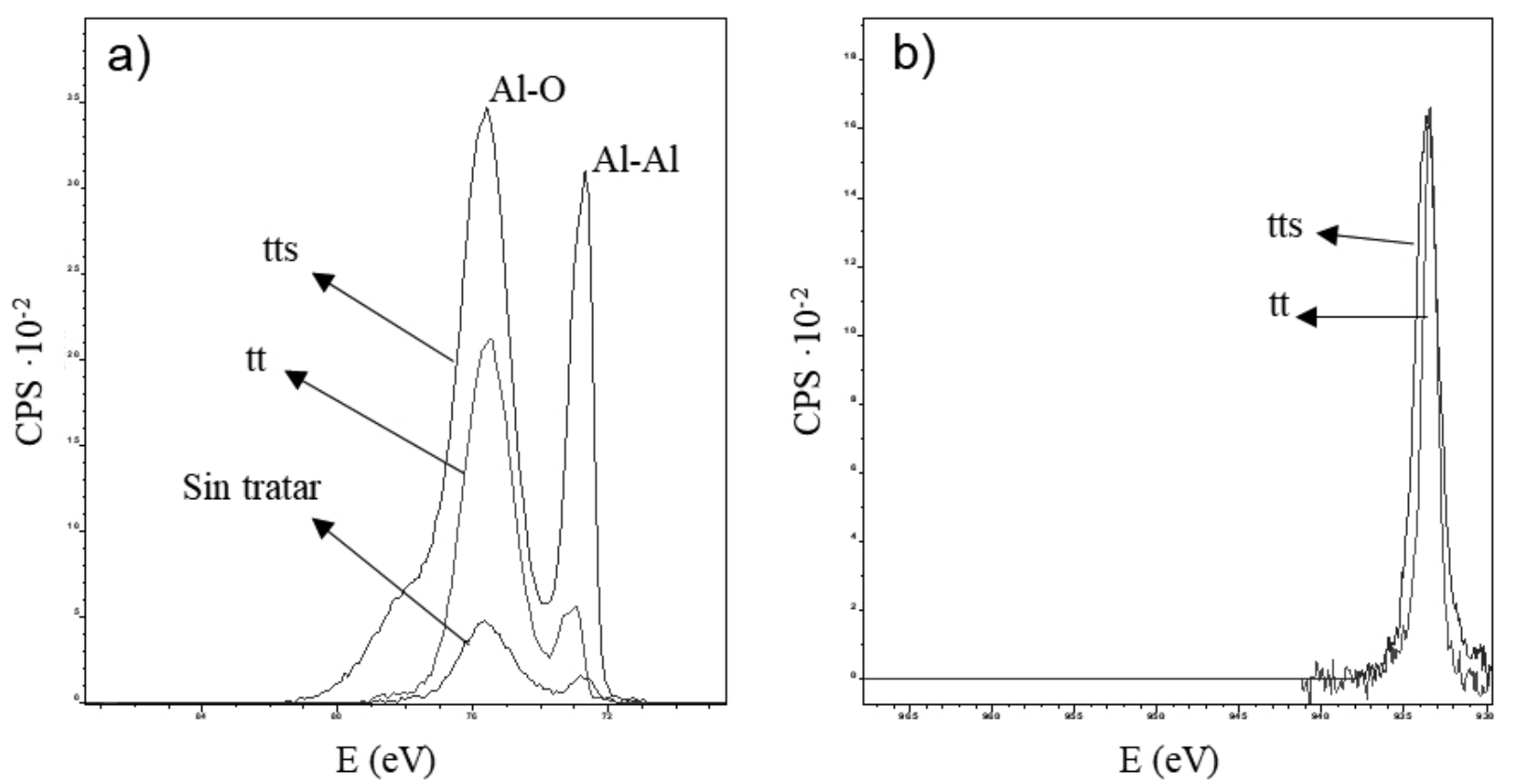

FigurA 5. Espectros XPS de $\mathrm{Al}$ y Cu $2 \mathrm{p}_{3 / 2}$.

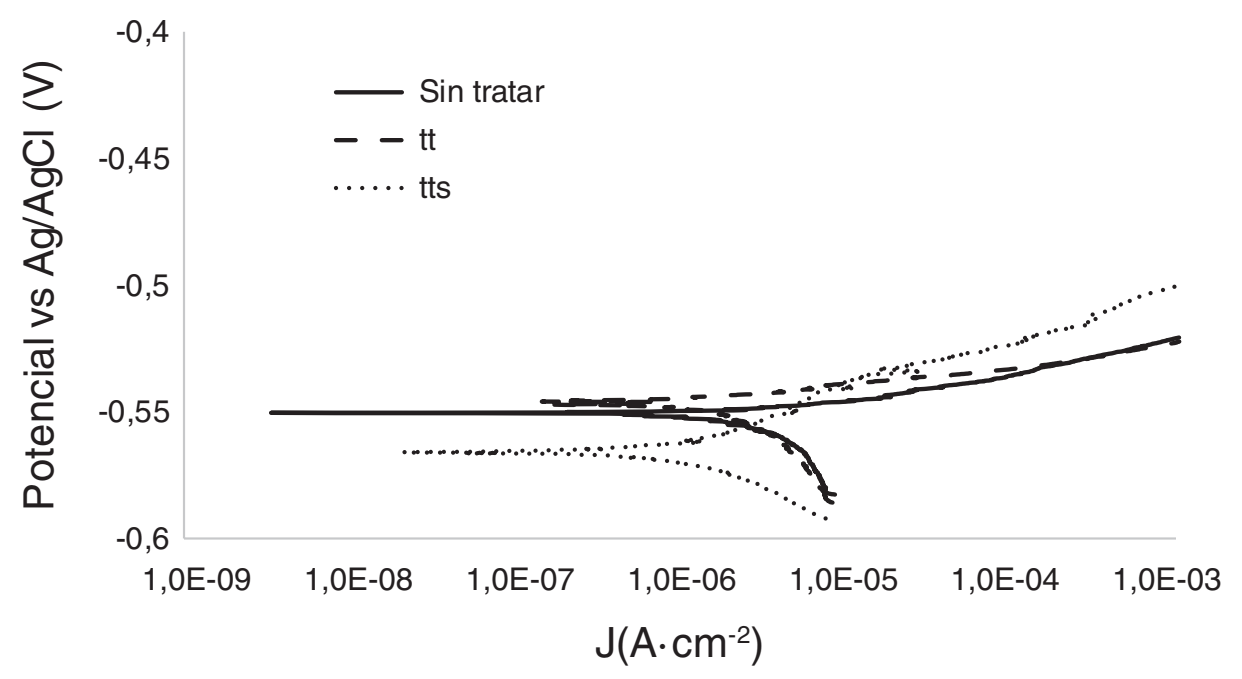

Figura 6. Curvas de polarización lineal de muestras sin tratar y tras los tratamientos tt y tts.

TABLA 2. Parámetros electroquímicos extraídos de la gráfica de la Fig. 6

\begin{tabular}{lccc}
\hline & Sin tratar & tt & tts \\
\hline $\mathbf{E}_{\text {ocp }}(\mathbf{V})$ & $-0,561$ & $-0,557$ & $-0,567$ \\
$\mathbf{E}_{\text {corr }}(\mathbf{V})$ & $-0,551$ & $-0,547$ & $-0,566$ \\
$\mathbf{E}_{\text {np }}(\mathbf{V})$ & $-0,540$ & $-0,540$ & $-0,540$ \\
$\mathbf{J}_{\text {corr }}\left(\mathbf{A} \cdot \mathbf{c m}^{-2}\right)$ & $1,50 \cdot 10^{-4}$ & $2,75 \cdot 10^{-4}$ & $6,84 \cdot 10^{-6}$ \\
$\mathbf{R}_{\mathbf{p}}\left(\mathbf{\Omega} \cdot \mathbf{c m}^{2}\right)$ & 173,58 & 94,49 & 3808,00 \\
\hline
\end{tabular}

los pretratamientos tts tiene un mayor contenido en la fase $\mathrm{Al}_{2} \mathrm{Cu}$ (Fase- $\theta$ ) que aquellas partículas que sí se desprenden. Adicionalmente, el aluminio no modifica su contenido, lo que indicaría bien que las condiciones del tratamiento, concentración, temperatura o tiempo no son suficientes para que se alcance la fase de oxidación del aluminio, o bien que, si se ha empezado a producir, los precipitados ya se han desprendido de la matriz, en cuyo caso no se han podido analizar. 
Por otro lado, el análisis de la señal Al 2p en XPS reveló una reducción del espesor de la alúmina de 6,4 hasta 3,2 $\mathrm{nm}$. Este ataque químico sobre la capa pasiva se debe principalmente a la existencia de los ácidos nítrico $(5-10 \% \mathrm{v} / \mathrm{v})$ y sulfúrico $(0,1-1 \% \mathrm{v} / \mathrm{v})$ en el Smut Go NC, dando lugar a la disolución de la capa de alúmina pasiva (Rayner-Canham, 2000), siguiendo la reacción química, Ec. (4):

$$
\mathrm{Al}_{2} \mathrm{O}_{3}(\mathrm{~s})+6 \mathrm{H}^{+}(\mathrm{aq}) \rightarrow 2 \mathrm{Al}^{3+}(\mathrm{aq})+3 \mathrm{H}_{2} \mathrm{O}(\mathrm{l})
$$

Además de esta reacción principal, existen otras que deben considerarse. La presencia de aniones $\mathrm{F}^{-}$en forma de $\mathrm{NaHF}_{2}$ también favorece la disolución de la alúmina mediante la formación de diversos fluoruros de aluminio (Rayner-Canham, 2000; Qi et al. 2016), tal como se muestra en la reacción de la Ec. (2), estando en este caso mucho más favorecida debido al bajo $\mathrm{pH}$ del medio, que es de 1,2. Asimismo, la presencia de cationes $\mathrm{Fe}^{3+}$ en forma de $\mathrm{Fe}_{2}\left(\mathrm{SO}_{4}\right)_{3}$, conlleva un ataque sobre la superficie de la matriz, dando lugar a una eliminación de aluminio y cobre metálico (Hughes et al., 2005; Qi et al., 2016) a través de las reacciones redox ilustradas en las reacciones químicas de las Ecs. (5) y (6).

$$
\begin{aligned}
& \mathrm{Fe}^{3+}(\mathrm{aq})+\mathrm{Al}(\mathrm{s}) \rightarrow \mathrm{Fe}^{2+}(\mathrm{aq})+\mathrm{Al}^{3+}(\mathrm{aq}) \\
& \mathrm{Fe}^{3+}(\mathrm{aq})+\mathrm{Cu}(\mathrm{s}) \rightarrow \mathrm{Fe}^{2+}(\mathrm{aq})+\mathrm{Cu}^{2+}(\mathrm{aq})
\end{aligned}
$$

No obstante, los resultados de XPS de la Fig. 5(b) muestran que el contenido en cobre es constante antes y después del decapado ácido con Smut Go. Este resultado discrepa con el notable aumento de cobre observado por diversos autores (Toh et al., 2004; Viroulaud et al., 2017) que fue atribuido a la disolución de cobre tanto de las fases $\mathrm{Al}(\mathrm{Cu}, \mathrm{Mg})$ como de la matriz y su posterior redeposición en la superficie del metal.

El análisis de los resultados obtenidos mediante los ensayos electroquímicos también aporta una valiosa información. Así, de la observación de las curvas de PL podemos concluir que la similitud entre las gráficas de polarización de las muestras no tratadas y las tt es acorde con lo observado en el análisis por SEM-EDX y XPS, pues al no producirse un elevado ataque en la superficie estudiada el comportamiento electroquímico mostrado es muy semejante. Los resultados electroquímicos de muestras sin tratar y tras los tratamientos tt dieron valores de potencial de nucleación de picaduras semejantes a $\mathrm{E}_{\text {corr }}$. Este hecho es típico en las aleaciones de aluminio de la serie 2XXX (Nieves et al., 2017).

Por el contrario, la curva obtenida tras el tratamiento tts muestra un desplazamiento de la rama catódica hacia valores menores de densidad de corriente y un descenso en el valor de $\mathrm{E}_{\text {corr }}$ respecto a las muestras no tratadas y a las muestras tt. Ambos hechos se traducen en una disminución de la actividad del sistema.

Numerosos autores establecen que $\mathrm{Al}(\mathrm{Cu}, \mathrm{Mg})$ es el principal intermetálico responsable de la corrosión por picaduras de aleaciones $\mathrm{Al}-\mathrm{Cu}$ (Aballe et al., 1998; Światowska-Mrowiecka et al., 2008; Boag et al., 2010; Zhou et al., 2012; Zhang et al., 2017; Tian et al., 2017). Por tanto, es de esperar que muestras con menor contenido en $\mathrm{Al}(\mathrm{Cu}, \mathrm{Mg})$ generen curvas de polarización desplazadas a densidades de corrientes menores que otra muestra con mayor cantidad de intermetálicos $\mathrm{Al}(\mathrm{Cu}, \mathrm{Mg})$.

Los intermetálicos $\mathrm{Al}(\mathrm{Cu}, \mathrm{Mg})$ inicialmente presentan un comportamiento anódico. Posteriormente, como se ha observado mediante SEM-EDX, durante el tratamiento en Smut Go sufren desaleación de $\mathrm{Mg}$, y el consiguiente enriquecimiento en $\mathrm{Cu}$ de los mismos modifica su comportamiento a catódico (Aballe et al., 1998, Obispo et al., 2000; Zhu y Van Ooij, 2003; Lacroix et al., 2008; Bethencourt et al., 2009; Bethencourt et al., 2012). Por su parte, los intermetálicos $\mathrm{Al}(\mathrm{Cu}, \mathrm{Fe}, \mathrm{Mn}, \mathrm{Si})$ presentan un comportamiento catódico desde el comienzo. El cambio de áreas anódica a catódicas asociado al comportamiento de los intermetálicos $\mathrm{Al}(\mathrm{Cu}, \mathrm{Mg})$ junto con la presencia del intermetálico catódico $\mathrm{Al}(\mathrm{Cu}, \mathrm{Fe}, \mathrm{Mn}, \mathrm{Si})$ pueden situar el potencial de corrosión en valores más activos en estas muestras (Dimitrov et al., 2000; Jones et al., 2005), como se aprecia en la Fig. 6.

\section{CONCLUSIONES}

La morfología de la aleación 2024-T3 no se vio afectada con el uso consecutivo de Turco 6849 y Turco 4215 NC-LT como limpiador alcalino. El empleo de Smut Go NC como decapante ácido afectó a la microestructura de la aleación, produciendo una disminución de la capa pasiva y provocando desaleación selectiva de $\mathrm{Mg}$ en los intermetálicos $\mathrm{Al}(\mathrm{Cu}, \mathrm{Mg})$.

Pueden distinguirse intermetálicos $\mathrm{Al}(\mathrm{Cu}, \mathrm{Mg})$ con $10 \%$ de $\mathrm{Mg}$ que permanecen en forma de esponja y con estequiometría $\mathrm{Al}_{2} \mathrm{Cu}$ tras el tratamiento completo de Turco 6849/Turco 4215 NC-LT/Smut Go mientras que otros con $20 \%$ de $\mathrm{Mg}$ se desprendieron. El diferente contenido en $\mathrm{Mg}$ es atribuido a la existencia de la fase $\mathrm{Al}_{2} \mathrm{Cu}$ (Fase- $\theta$ ) junto a la fase $\mathrm{Al}_{2} \mathrm{CuMg}$ (Fase-S).

El uso de Turco 4215 NC-LT no provocó ninguna modificación reseñable en el comportamiento electroquímico de la aleación. Por el contrario, el uso de Smut Go NC sí modificó las curvas PL. Se produjo un desplazamiento de la rama catódica 
hacia menores valores de densidades de corriente atribuido a la eliminación de parte de los intermetálicos $\mathrm{Al}(\mathrm{Cu}, \mathrm{Mg})$, que es el principal responsable de los procesos de corrosión por nucleación de picadura. Asimismo, el potencial de corrosión se desplazó a valores más negativos, hecho justificado por el viraje de comportamiento electroquímico de anódico a catódico de los intermetálicos Fase-S fruto de la desaleación selectiva en magnesio.

\section{AGRADECIMIENTOS}

Este proyecto ha sido financiado por el Ministerio de Economía, Industria y Competitividad/ Programa FEDER (Proyecto MAT2014-60857-R).

\section{REFERENCIAS}

Aballe, A., Bethencourt, M., Botana, F.J., Marcos, M., Rodríguez, M.A. (1998). Seguimiento de la corrosión de la aleación AA2024 en disoluciones de $\mathrm{NaCl}$ mediante la medida del ruido electroquímico. Rev. Metal. 34 ( ${ }^{\circ}$ Ext.), 42-46. https://doi.org/10.3989/revmetalm.1998.v34.iExtra

Bethencourt, M. Botana, F.J. Cano, M.J., Marcos, M., Sánchez-Amaya, J.M., González-Rovira, L. (2009). Behaviour of the alloy AA2017 in aqueous solutions of $\mathrm{NaCl}$. Part I: Corrosion mechanisms. Corros. Sci. 51 (3), 518-524. https://doi.org/10.1016/j.corsci.2008.12.027.

Bethencourt, M., Botana, F.J., Cano, M.J., Gonzalez-Rovira, L., Marcos, M., Sánches-Amaya, J.M. (2012). Protection by Thermal and Chemical Activation with Cerium Salts of the Alloy AA2017 in Aqueous Solutions of NaCl. Metall. Mater. Trans. A. 43 (1), 182-194. https://doi.org/10.1007/ s11661-011-0858-x

Boag, A., Hughes, A.E., Wilson, N.C., Torpy, A., MacRae, C.M., Glenn, A.M., Muster, T.H.'(2009). How complex is the microstructure of AA2024-T3?. Corros. Sci. 51 (8), 1565-1568. https://doi.org/10.1016/j.corsci.2009.05.001.

Boag, A., Taylor, R.J., Muster, T.H., Goodman, N., McCulloch, D., Ryan, C., Rout, B., Jamieson, D., Hughes, A.E. (2010). Stable pit formation on AA2024-T3 in a $\mathrm{NaCl}$ environment. Corros. Sci. 52 (1), 90-103. https://doi.org/10.1016/j. corsci.2009.08.043

Cerezo, J., Taheri, P., Vandendael, I., Posner, R., Lill, K., de Wit, J.H.W., Mol, J.M.C., Terryn, H. (2014). Influence of surface hydroxyls on the formation of $\mathrm{Zr}$-based conversion coatings on AA6014 aluminum alloy. Surf. Coat. Tech. 254, 277-283. https://doi.org/10.1016/j. surfcoat.2014.06.030.

DeRose, J.A., Suter, T., Balkowiec, A., Michalski, J., Kurzydlowski, K.J., Schmutz, P. (2012). Localised corrosion initiation and microstructural characterisation of an $\mathrm{Al}$ 2024 alloy with a higher $\mathrm{Cu}$ to $\mathrm{Mg}$ ratio. Corros. Sci. 55, 313-325. https://doi.org/10.1016/j.corsci.2011.10.035.

Dimitrov, N., Mann, J.A., Vukmirovic. M., Sieradzki. K. (2000). Dealloying of $\mathrm{Al}_{2} \mathrm{CuMg}$ in Alkaline Media. J. Electrochem. Soc. 147 (9), 3283-3285. https://doi. org/10.1149/1.1393896.

Eichinger, E., Osborne. J., Van Cleave, T. (1997). Hexavalent chromium elimination: An aerospace industry progress report. Met. Finish 95 (3), 36-41. https://doi.org/10.1016/ S0026-0576(97)86771-2.

Gao, M., Feng, C.R., Wei, R.P. (1998). An Analytical electron microscopy study of constituent particles in commercial 7075-T6 and 2024-T3 Alloys. Metall. Mater. Tans. A. 26 (4), 1145-1151. https://doi.org/10.1007/s11661-998-0240-9.

González Fernández, J.A. (1989). Control de la Corrosion. Estudio y medida por técnicas electroquímicas, Editorial CSIC, Madrid.

Glenn, A.M., Hughes, A.E., Muster, T.H., Lau, D., Wilson, N.C., Torpy, A., MacRae, C.M., Ward, J. (2013). Investigation into the influence of carbon contamination on the corrosion behaviour of Aluminum microelectrodes and AA2024-T32013. J. Electrochem. Soc. 160 (3), 119-127. https://doi.org/10.1149/2.047303jes.

Guillaumin, V., Mankowski, G. (1998). Localized corrosion of 2024 T351 aluminium alloy in chloride media. Corros. Sci. 41 (3), 421-438. https://doi.org/10.1016/ S0010-938X(98)00116-4.

Guo. Y., Frankel, G.S. (2012). Characterization of trivalent chromium process coating on AA2024-T3. Surf. Coat. Tech. 206 (19-20), 3895-3902. https://doi.org/10.1016/j. surfcoat.2012.03.046.

Harvey, T.G. (2013). Cerium-based conversion coatings on aluminium alloys: a process review. Corros. Eng. Sci. Techn. 48 (4), 248-269. https://doi.org/10.1179/17432782 13 Y.0000000089.

Hughes, A.E., Harvey, T.G., Nikpour, T., Muster, T.H., Hardin, S.G. (2005). Non-chromate deoxidation of AA2024$\mathrm{T} 3$ using $\mathrm{Fe}(\mathrm{III})-\mathrm{HF}-\mathrm{HNO}_{3}$. Surf. Interface Anal. 37 (1), 15-23. https://doi.org/10.1002/sia.1998.

$\mathrm{I}+\mathrm{D}+\mathrm{P}-072$ (2009). Cleaning and pickling of aluminium and its alloys. Airbus Specification, Last revision: May 2009. https://w13.airbus.com/airbussupply.

Jones, M.J., Heurtier, P., Desrayaud, C., Montheillet, F., Allehaux, D., Driver, J.H. (2005). Correlation between microstructure and microhardness in a friction stir welded 2024 aluminium alloy. Scripta Mater. 52 (8), 693-697. https:// doi.org/10.1016/j.scriptamat.2004.12.027.

Kendig, M.W., Buchheit, R.G. (2003). Corrosion inhibition of aluminum and aluminum alloys by soluble chromates, chromate coatings, and chromate-free coatings. Corrosion 59 (5), 379-400. https://doi.org/10.5006/1.3277570.

Kulinich, S.A., Akhtar, A.S. (2012). On Conversion Coating Treatments to Replace Chromating for Al Alloys: Recent Developments and Possible Future Directions. Russ. J. Non-Ferr. Met. 53 (2), 176-203. https://doi.org/10.3103/ S1067821212020071.

Lacroix, L., Ressier, L., Blanc, C., Mankowski, G. (2008). Combination of AFM, SKPMF and SIMD to study the corrosion behaviour of S-phase particles in AA2024T351. J. Electrochem. Soc. 155 (4), 131-137. https://doi. org/10.1149/1.2833315.

Li. L., Desouza, A.L., Swaing, G.M. (2014). Effect of deoxidation pretreatment on the corrosion inhibition provided by a trivalent chromium process (TCP) conversion coating on AA2024-T3. J. Electrochem. Soc. 161 (5), 246-253. https:// doi.org/10.1149/2.031405jes.

Moffitt, C.E., Wieliczka, D.M., Yasuda, H.K. (2001). An XPS study of the elemental enrichment on aluminium alloy surfaces from chemical cleaning. Surf. Coat. Tech. 137 (2-3), 188-196. https://doi.org/10.1016/S0257-8972(00)01121-X.

Montemor, M.F. (2014). Functional and smart coatings for corrosion protection: A review of recent advances. Surf. Coat. Tech. 258, 17-37. https://doi.org/10.1016/j. surfcoat.2014.06.031

Nieves, C., Remolina, E.N., Hernández, C.A., Rueda, L.M., Coy, A.E., Viejo, F. (2017). Síntesis, caracterización y evaluación de la resistencia a la corrosión de recubrimientos híbridos Sol-Gel base TEOS/MPS sobre la aleación AA2050-T8. Rev. Metal. 53 (4), e106. https://doi. org/10.3989/revmetalm.106.

Obispo, H.M., Murr, L.E., Arrowood, R.M., Trillo, E.A. (2000). Copper deposition during the corrosion of aluminum alloy 2024 in sodium chloride solutions. J. Mater. Sci. 35 (14), 3479-3495. https://doi.org/10.1023/A:1004840908494.

Osborne, J.H. (2001). Observations on chromate conversion coatings from a sol-gel perspective. Prog. Org. Coat. 41 (4), 280-286. https://doi.org/10.1016/S0300-9440(01)00143-6.

Pinc, W., Geng, S., O'Keefe, M., Fahrenholtz, W., O'Keefe, T. (2009). Effects of acid and alkaline based surface preparations on spray deposited cerium based conversion coatings on Al 2024-T3. Appl. Surf. Sci. 255 (7), 4061-4065. https:// doi.org/10.1016/j.apsusc.2008.10.110.

Qi, J.-T., Hashimoto, T., Walton, J.R., Zhou, X., Skeldon, P., Thompson, G.E. (2015). Trivalent chromium conversion coating formation on aluminium. Surf. Coat. Tech. 280, 317-329. https://doi.org/10.1016/j.surfcoat.2015.09.024. 
Qi, J., Nemcova, A., Walton, J.R., Zhou, X., Skeldon, P., Thompson, G.E. (2016). Influence of pre- and post-treatments on formation of a trivalent chromium conversion coating on AA2024 alloy. Thin. Solid. Films 616, 270-278. https://doi. org/10.1016/j.tsf.2016.08.044.

Rayner-Canham, G., (2000). Química Inorgánica Descriptiva, Pearson, Nueva York.

Strohmeier, B.R. (1990). An ESCA method for determinaning the oxide thickness on aluminium alloy. Surf. Interface. Anal. 15 (1), 51-56. https://doi.org/10.1002/sia.740150109.

Światowska-Mrowiecka, J., Zanna, S., Ogle, K., Marcus, P. (2008). Adsorption of 1,2-diaminoethane on $\mathrm{ZnO}$ thin films from p-xylene. Appl. Surf. Sci. 254 (17), 5530-5539. https://doi.org/10.1016/j.apsusc.2008.02.170.

Tian, W., Li, S., Liu, J., Yu, M., Du, Y. (2017). Preparation of bimodal grain size 7075 aviation aluminum alloys and their corrosion properties. Chinese. J. Aeronaut. 30 (5), 1777 1788. https://doi.org/10.1016/j.cja.2017.06.001.

Tiringer, U., Kovac, J., Milosev, I. (2017). Effects of mechanical and chemical pre-treatments on the morphology and composition of surfaces of aluminium alloys 7075-T6 and 2024-T3. Corros. Sci. 119, 46-59. https://doi.org/10.1016/j. corsci.2017.02.018

Toh, S.K., Hughes, A.E., McCulloch, D.G., duPlessis, J., Stonham, A. (2004). Characterization of non-Cr-based deoxidizers on Al alloy 7475-T7651. Surf. Interface. Anal. 36 (12), 1523-1532. https://doi.org/10.1002/sia.1938.
Twite, R.L., Bierwagen, G.P. (1998). Review of alternatives to chromate for corrosion protection of aluminum aerospace alloys. Prog. Org. Coat. 33 (2), 91-100. https://doi. org/10.1016/S0300-9440(98)00015-0.

Viroulaud, R., Swiatowska, J., Seyeux, A., Zanna, S., Tardelli, J., Marcus, P. (2017). Influence of surface pretreatments on the quality of trivalent chromium process coatings on aluminum alloy. Appl. Surf. Sci. 423, 927-938. https://doi. org/10.1016/j.apsusc.2017.06.246.

Yasakau, K.A., Zheludkevich, M.L., Lamaka, S.V., Ferreira, M.G.S. (2006). Mechanism of Corrosion Inhibition of AA2024 by Rare-Earth Compounds. J. Phys. Chem. B. 110 (11), 5515-5528. https://doi.org/10.1021/jp0560664.

Zhang, X., Zhou, X., Hashimoto, T., Liu, B. (2017). Localized corrosion in AA2024-T351 aluminium alloy: Transition from intergranular corrosion to crystallographic pitting. Mater. Charact. 130, 230-236. https://doi.org/10.1016/j. matchar.2017.06.022.

Zhou, X., Luo, C., Hashimoto, T., Hughes, A.E., Thompson, G.E. (2012). Study of localized corrosion in AA2024 aluminium alloy using electron tomography. Corros. Sci. 58, 299-306. https://doi.org/10.1016/j.corsci.2012.02.001.

Zhu, D., Van Ooij, W.J. (2003). Corrosion protection of AA 2024-T3 by bis-[3-(triethoxysilyl)propyl]tetrasulfide in sodiumchloride solution. Part 2: mechanism for corrosion protection. Corros. Sci. 45 (10), 2177-2197. https://doi. org/10.1016/S0010-938X(03)00061-1. 